\title{
Life history of Aptesis nigrocincta (Hymenoptera: Ichneumonidae) a cocoon parasitoid of the apple sawfly, Hoplocampa testudinea (Hymenoptera: Tenthredinidae)
}

\author{
D. Babendreier* \\ CABI Bioscience Centre Switzerland, CH-2800 Delémont, Switzerland
}

\begin{abstract}
Aptesis nigrocincta Gravenhorst is a bivoltine ectoparasitoid of apple sawfly cocoons, hosts that must be found and parasitized by females at a depth of $10-25 \mathrm{~cm}$ in the soil. Females are significantly smaller than males and nearly wingless. After encountering a host, females needed $29.3 \mathrm{~min}$ at $20^{\circ} \mathrm{C}$ and $19.9 \mathrm{~min}$ at $25^{\circ} \mathrm{C}$ to deposit an egg on the host. Development from egg to adult took 39.6 days for females and 38.0 days for males at $20^{\circ} \mathrm{C}$. This small difference was significant. At $20^{\circ} \mathrm{C}$, the longevity of females that had no opportunity to oviposit was on average 72.5 days, significantly higher than male longevity (50.6 days). The longevity of females given access to hosts throughout their lifetime averaged 58.6 days. Females were able to mate immediately after emergence and copulation lasted on average $21.7 \mathrm{~s}$. After a pre-oviposition period averaging 5.8 days, females laid 20.2 eggs during their lifetime, thus less than one egg per day. Neither the fecundity nor longevity of individual females was correlated with body size. If females were deprived of food, longevity as well as lifetime fecundity were drastically reduced. Field studies were carried out in one organically managed apple orchard in Switzerland. Aptesis nigrocincta showed parasitism rates ranging from 12.1 to $39.7 \%$ within single parasitoid generations, thereby constituting the most important mortality factor of apple sawfly cocoons.
\end{abstract}

\section{Introduction}

The European apple sawfly, Hoplocampa testudinea Klug (Hymenoptera: Tenthredinidae), is a well known univoltine pest species of apples in all major apple growing areas of Europe. Apple sawfly larvae feed exclusively on apple fruitlets. Mature larvae then drop to the ground, burrow into the soil and form a tough cocoon at a depth of about $10-25 \mathrm{~cm}$. In the late $1930 \mathrm{~s}$, this pest was accidentally introduced into the United States and in 1979 it was first

*Present address: Federal Research Station for Agroecology, 8046 Zürich, Switzerland

Fax: +41 13777201

E-mail: dirk.babendreier@fal.admin.ch detected in eastern Canada. It has since spread through most apple growing areas of Quèbec, where it caused considerable damage (Vincent \& Mailloux, 1988), and recently invaded the Ottawa valley (U. Kuhlmann, personal communication). A biological control programme was started at CABI Bioscience Centre Switzerland (formerly International Institute of Biological Control) in 1992 to determine the natural parasitoid complex in Europe. Favourable natural enemies could then be introduced into Canada and act as biological agents within the framework of integrated pest management to reduce the pesticide load in affected Canadian apple orchards. Extensive surveys in central Europe revealed a rather small parasitoid complex, of two larval parasitoids and one cocoon parasitoid (unpublished CABI Bioscience Annual Reports 1995-1997). The larval endoparasitoid Lathrolestes ensator Brauns 
(Hymenoptera: Ichneumonidae) was selected and is currently being released in Canada, whereas the cocoon ectoparasitoid Aptesis nigrocincta Gravenhorst (Hymenoptera: Ichneumonidae) is considered as an additional potential biological control agent.

The ichneumonid $A$. nigrocincta belongs to the subfamily Cryptinae (= Phygadeuontinae, Horstmann, 1993). Many species of this subfamily are known to be ectoparasitoids, typically parasitizing larvae within several taxonomic groups in cryptic habitats (Clausen, 1940). However, a considerable number of species of this subfamily parasitize prepupae and pupae. Females of these species are often brachypterous or even apterous. Recently Horstmann (1993) reviewed this group, whereafter A. nigrocincta is the only brachypterous species of its genus. Despite some recent taxonomic insights, little is known about the hosts and biology of most Aptesis species, including $A$. nigrocincta. Host records in the literature are scarce for A. nigrocincta as is the case for many species parasitizing cocoons below ground level. This parasitoid was first recorded to attack apple sawfly under the synonym Microcryptus nigrocincta Gravenhorst in Lithuania by Zajanekauskas (1963) and later by Skorikova (1969, cited in Jaworska, 1987) near Moscow, Russia. Aptesis nigrocincta has been reared from the sawflies Pristiphora abietina Christ (Ohnesorge, 1957) and Caliroa cerasi Linnaeus (Hymenoptera: Tenthredinidae) (Carl, 1976). Other records remain doubtful, such as Kopelke (1986), where A. nigrocincta was described as a larval endoparasitoid of the sawfly Pontania dolichura Thomson (Hymenoptera: Tenthredinidae).

It is generally accepted that knowledge of the biology of potential biocontrol agents and their impact on host populations is crucial to enhance the chance of success of biological control programmes (e.g. Waage, 1990). Apple sawfly cocoons are available from June onwards throughout the season and during this time A. nigrocincta builds up one complete and another partial generation (Babendreier, 1999). Adults emerge in June from parasitized hosts to search for newly formed host cocoons. Eggs laid by these females either develop directly to emerge in August, emerge in October/November to hibernate as adults (only females can hibernate successfully in that stage) or stay inside the cocoon until the following June (Babendreier, 1999). Many important biological attributes remain unknown, however. Therefore, the objective of this study is to investigate the life history of A. nigrocincta, in order to contribute to the knowledge of this less known group of parasitoids, and to evaluate its potential as a biological control agent against $H$. testudinea in Canada.

\section{Materials and methods \\ Culture of hosts and parasitoids}

Host cocoons for the rearing of parasitoids were obtained from collections of apples infested by late instars of $H$. testudinea in the field. Apples were placed on wire screens which were suspended over plastic trays to receive the descending larvae. All larvae were removed twice a day and allowed to burrow into soil in plastic cylinders $(1.3 \mathrm{l})$ where they formed cocoons. The first individuals of $A$. nigrocincta were obtained by collections of apple sawfly cocoons in one organically managed apple orchard in north-eastern
Switzerland in 1994. Emerging parasitoids were determined and a culture was established and maintained in the laboratory. All female parasitoids used for experiments were kept singly in Petri dishes $(94 \mathrm{~mm})$ at $20^{\circ} \mathrm{C}$ and provided with honey and water ad libitum. Males used in the rearing were held under the same environmental conditions but kept in groups of up to 15 individuals in 1.31 plastic vials.

\section{Mating and oviposition behaviour}

Single males of $A$. nigrocincta were released into a Petri dish of $94 \mathrm{~mm}$ diameter with single unmated females under laboratory conditions $\left(20^{\circ} \mathrm{C}\right)$ and observed continuously $(\mathrm{n}=$ 48); the duration of mating was recorded. In another experiment (also at $20^{\circ} \mathrm{C}$ ), males were confronted with females that had mated two days previously $(n=15)$. In order to achieve ovipositions, Petri dishes were filled with a layer of soil of approximately $3 \mathrm{~mm}$ and a single healthy cocoon was placed on the surface of the soil. Single mated females were then released and allowed to oviposit. The duration of an ovipositon bout, here defined as the time from the first contact with a host to withdrawal of the ovipositor, was recorded at $20^{\circ} \mathrm{C}$ and $25^{\circ} \mathrm{C}$. Cocoons were dissected for the presence of eggs.

\section{Development}

Developmental times of different stages were studied in the laboratory at two constant temperatures $\left(20^{\circ} \mathrm{C}\right.$ and $25^{\circ} \mathrm{C}$ ) under a light regime of 16:8 L:D and at $85 \pm 10 \%$ r.h. Single females $(n=180)$ were given access to a single randomly chosen host cocoon in Petri dishes at $20 \pm 1^{\circ} \mathrm{C}$. Parasitized cocoons were put into a climate chamber immediately after the female completed oviposition. In order to investigate the egg hatching pattern, a first set of cocoons was opened $24 \mathrm{~h}$ after oviposition and checked for hatched first instar larvae every $2 \mathrm{~h}$ for the $20^{\circ} \mathrm{C}$ treatment and every hour for the $25^{\circ} \mathrm{C}$ treatment. Observations on egg hatching were made between $0700 \mathrm{~h}$ and $2100 \mathrm{~h}$. Larval development could not be investigated separately from egg development because preliminary results had shown that most larvae were not able to complete development after an early dissection of the cocoon. Therefore, a second set of parasitized cocoons was left intact until the seventh day after oviposition and then carefully opened. Afterwards, cocoons were checked daily until the host larvae were completely consumed. This time was taken as a measurement for both egg and larval development together. A third set of parasitized cocoons was left intact from the time of oviposition until emergence of adults. Cocoons were checked for emergence daily at noon. Cocoons without any emergence hole were dissected one week after the last adult emerged.

\section{Longevity}

Longevity of $A$. nigrocincta was only investigated at $20^{\circ} \mathrm{C}$, 16:8 L:D and $85 \pm 10 \%$ r.h. conditions. All adults $(n=60$ males and 25 females) were kept singly in Petri dishes of $94 \mathrm{~mm}$ diameter and provided with cotton sticks, soaked with water and a drop of honey. Both the honey and the cotton sticks were replenished at weekly intervals and care was taken to keep cotton sticks wet. Note that females in this trial had no opportunity to oviposit. Petri dishes were 
checked every day for mortality and the hind tibia length of each individual was measured at death under a microscope (magnification $40 \times$ ).

\section{Fecundity}

In order to investigate the initial eggload, 20 females were deep frozen on the day of emergence and later dissected in insect saline under a microscope (magnification $10 \times$ ). An experiment on lifetime fecundity was designed as follows. From the day of emergence, a group of 25 females were kept singly in Petri dishes at $20^{\circ} \mathrm{C}, 16: 8 \mathrm{~L}: \mathrm{D}$ and $85 \pm$ $10 \%$ r.h. and allowed to oviposit into one healthy host cocoon every day. This low rate was chosen because preliminary investigations had shown that females were generally not able to lay more than one egg per day (Babendreier, unpublished results). Cocoons left by the female were removed and dissected on the same day for parasitoid eggs. After death, females were deep-frozen, the hind-tibia length was measured and the number of eggs remaining in the ovaries was counted. Egg size was measured once for the third egg laid by each female, after a lifetime of four weeks and then again for the first egg a female laid after she survived for 50 days. In an analogous experiment, another group of females was also provided with one cocoon per day but kept with access solely to water.

To investigate possible body size differences between the sexes, males and females were deep-frozen on the day of emergence, put in a desiccator at $95^{\circ} \mathrm{C}$ for $6 \mathrm{~h}$ and then weighed. Another group of males and females previously used in the rearing $\left(\right.$ at $20^{\circ} \mathrm{C}$ ), which died naturally after about two months, were weighed after the same drying procedure. All individuals emerged from the same sample of cocoons.

\section{Field parasitism}

A field experiment was designed to investigate the impact of $A$. nigrocincta on populations of the apple sawfly. An organically managed orchard of about 1 ha where $H$. testudinea was present for at least ten years was chosen for this experiment. This orchard was located near to Zuckenriet in north-eastern Switzerland. Wooden frames $(30$ by $30 \mathrm{~cm}$ and $7 \mathrm{~cm}$ height) with wirescreen on the underside were filled with approximately $3 \mathrm{~cm}$ of field collected soil. Sixty healthy apple sawfly cocoons were added and covered with another $4 \mathrm{~cm}$ of field collected soil. Four of these frames were exposed to parasitism below apple trees (variety Idaret) in 1995 and eight frames in 1996 and 1997, respectively. In 1995 this experiment was set up only once from June to August while cocoons were exposed twice a year in 1996 and 1997 to coincide with the main and partial second generation of $A$. nigrocincta (for exact dates see table 1). Each frame was sunk into the ground at a depth of $15 \mathrm{~cm}$ and covered with an additional layer of soil and grass in the orchard to reduce the risk of desiccation and to approach field conditions. After an exposure period of about six weeks, cocoons were brought into the laboratory, washed out of the soil and kept under near field conditions in an insectary. Rates of parasitism were calculated from emerging adults and subsequent dissections.

\section{Results}

\section{Mating and oviposition behaviour}

Following emergence, adults normally groomed and fed. Soon after their release in a Petri dish, males tried to approach females with wings vibrating rapidly. The male then mounted the wingless female and immediately bent down his abdomen to make contact with the female genitalia. Copulation lasted $21.7 \pm 3.4 \mathrm{~s}(\mathrm{n}=48 \pm \mathrm{SD})$. After copulation, females resisted further mating attempts. Even hibernated females that had mated in October very seldom mated a second time when given the opportunity the following June, i.e after about eight months. In contrast, males mated repeatedly, but showed no wing vibrations when enclosed in a Petri dish together with a mated female.

In laboratory observations, females did not show orientated movements towards host cocoons. They searched the surface randomly accompanied by antennal tapping on the substrate. Host cocoons may be passed at only $1 \mathrm{~cm}$ distance indicating that visual cues are not important. When in contact with a host cocoon the female mounted it and investigated the surface with her antennae. The female then invariably bent down the abdomen and probed the host with her ovipositor several times. From the first contact with a host cocoon to withdrawal of the ovipositor, females needed $29.3 \pm 14.9 \mathrm{~min}(\mathrm{n}=137)$ to complete an oviposition. After the initial probing and drilling process (which lasted for 1.5 to $6 \mathrm{~min}$ ) females stood nearly motionless for the remaining oviposition time. In all cases where it could be assured that the female visited the host cocoon only once, a single egg was found after oviposition $(n=35)$.

Table 1. Percentage mortality of Hoplocampa testudinea cocoons obtained from a field exposure experiment in Switzerland with mortality determined by dissection.

\begin{tabular}{lccccc}
\hline Year & $\begin{array}{c}1995 \\
\text { Exposure period }\end{array}$ & $\begin{array}{c}\text { 1996a } \\
\text { 22 Jun-8 Aug }\end{array}$ & $\begin{array}{c}\text { 1996b Jun-6 Aug } \\
\text { 6 Aug-10 Sep }\end{array}$ & $\begin{array}{c}\text { 1997a } \\
\text { 16 Jun-6 Aug }\end{array}$ & $\begin{array}{c}\text { 1997b } \\
\text { 6 Aug-22 Sep }\end{array}$ \\
\hline Cocoons exposed & 240 & 480 & 480 & 480 & 480 \\
Cocoons recovered* & 200 & 405 & 454 & 406 & 397 \\
Mortality factors \% & & & & & \\
$\quad$ Aptesis nigrocincta & 19.0 & 12.1 & 39.7 & 17.5 & 13.4 \\
general predators & 8.5 & 2.7 & 5.3 & 7.4 & 16.1 \\
Paecilomyces spp. & 3.0 & 2.2 & 6.4 & 6.6 & 4.8 \\
$\quad$ unknown factors & 4.0 & - & 2.2 & 3.2 & 0.25 \\
Total mortality & 34.5 & 17.3 & 53.5 & 34.7 & 34.5 \\
\hline
\end{tabular}

${ }^{*} 100 \%$. 


\section{Development}

At $20^{\circ} \mathrm{C}$, egg hatching took place between $72 \mathrm{~h}$ and $96 \mathrm{~h}$ after oviposition and $50 \%$ of the parasitoid eggs hatched within $80 \mathrm{~h}(\mathrm{n}=28)$. At $25^{\circ} \mathrm{C}, 50 \%$ of eggs hatched within $47 \mathrm{~h}$ and all eggs hatched between $43 \mathrm{~h}$ and $54 \mathrm{~h}$ after being laid $(n=30)$. Under the experimental conditions, egg hatching was complete in both treatments, i.e. no mortality occurred during the egg stage. In two instances out of 30 , no eggs were laid by the parasitoid female. Development from the time of oviposition to the mature larvae took $11.5 \pm 1.5$ days at $20^{\circ} \mathrm{C}(n=26)$ and $8.4 \pm 0.93$ days at $25^{\circ} \mathrm{C}(\mathrm{n}=25)$. By that time all the host tissue was consumed but cocoon formation had not begun. Under the $20^{\circ} \mathrm{C}$ temperature regime, the development from oviposition to the eclosion of adults took $39.6 \pm 2.4$ days for females $(n=18)$ and $38.0 \pm 2.2$ days for males $(\mathrm{n}=25)$. This small difference was significant $\left(t_{41}=2.28, P<0.05\right)$. At $25^{\circ} \mathrm{C}$, the development took $26.1 \pm 1.1$ days for females $(\mathrm{n}=11)$ and $25.0 \pm 1.8$ days for males $(\mathrm{n}=$ $53)$, a difference that was not quite significant $\left(\mathrm{t}_{62}=1.70,0.1\right.$ $>P>0.05)$

\section{Longevity}

At $20^{\circ} \mathrm{C}$, males of this parasitoid species lived $50.6 \pm 17.9$ ( $\mathrm{n}=59$ ) days while females that had no opportunity to oviposit survived significantly longer $(72.5 \pm 34.1$ days, $\mathrm{n}=$ $25 ; U_{59,25}=450.5, P<0.01$, see fig. 1$)$. Females that were used in the lifetime fecundity test and thus laid as many eggs as they were able to, lived for $58.6 \pm 21.2$ days $(n=25)$ thereby showing a longevity intermediate between that of males and females who did not oviposit at all (see fig. 1). A MannWhitney U-test, however, showed no significant difference, either between the longevity of females used in the fecundity experiment and the longevity of males $\left(\mathrm{U}_{59,25}=\right.$ $564,0.1>P>0.05)$ or between the longevity of females used in the fecundity experiment and host-deprived females $\left(\mathrm{U}_{25,25}=247.5, P>0.05\right)$.

\section{Fecundity}

On the day of emergence, no mature eggs were found in the ovaries of females $(n=20)$ but instead there were many immature eggs and a large quantity of fat reserves in the abdomen; each ovary contained four ovarioles $(n=45)$. From the lifetime fecundity experiment, a mean preoviposition period of $5.75 \pm 3.0$ days $(n=25)$ could be ascertained. However, as a result of the high variability of this period, two females were observed laying their first eggs already by the second day of the experiment (fig. 2). This experiment further revealed that females were able to lay on average only $20.2 \pm 5.4$ eggs during their whole life, with a range from 8 to 32 eggs $(n=25$, fig. 2$)$. After the preoviposition period had ceased, a peak period of egglaying occurred until females were about 3-4 weeks old (see fig. 2). Later in their life, females were able to lay only about one egg every 3-4 days. Dissections of females after death revealed that the ovaries of most females were completely empty at that time; only one female had a single mature egg in the ovary and the ovaries of two other females contained a very few immature eggs. The post-reproductive lifetime lasted $10.3 \pm 8.1$ days $(n=25)$.

Females that were provided with water only but had no access to any other food source, lived for $26.8 \pm 6.3$ days ( $\mathrm{n}=$ $10)$ but had a very limited lifetime fecundity $(3.8 \pm 2.3$ eggs, $\mathrm{n}=10$ ).

The longevity of females in the lifetime-fecundity experiment was not related to female size $\left(\mathrm{r}^{2}=0.028, \mathrm{~F}_{1,23}=\right.$ $0.667, P>0.05)$ nor was there a relationship between the number of eggs laid per female and female body size $\left(\mathrm{r}^{2}=\right.$ $\left.0.018, \mathrm{~F}_{1,23}=0.425, P>0.05\right)$. In contrast, a correlation between the longevity of females and the number of eggs laid during the life was obtained $(r=0.454, P<0.05$, Spearman rank correlation) and a weak but significant relationship was obtained for longevity and body size of male parasitoids $\left(\mathrm{r}^{2}=0.163, \mathrm{~F}_{1,57}=11.11, P<0.01\right)$.

The size of the eggs laid early in the life of the wasps averaged $1.10 \pm 0.054 \mathrm{~mm}$ in length and $0.287 \pm 0.012 \mathrm{~mm}$ at the widest part of the egg $(n=25)$ and no significant decrease was found for either length $\left(1.08 \pm 0.061 \mathrm{~mm} ; Z_{22,22}\right.$ $=0.50, P=0.61)$ or width $\left(0.284 \pm 0.014 \mathrm{~mm} ; \mathrm{Z}_{22,22}=0.41, \stackrel{2,22}{=}\right.$ 0.68 , Wilcoxon matched pairs signed rank test) of eggs laid by females after a lifetime of four weeks. However, eggs that females laid after a lifetime of 50 days significantly decreased in size and measured only $0.918 \pm 0.124 \mathrm{~mm}$ in

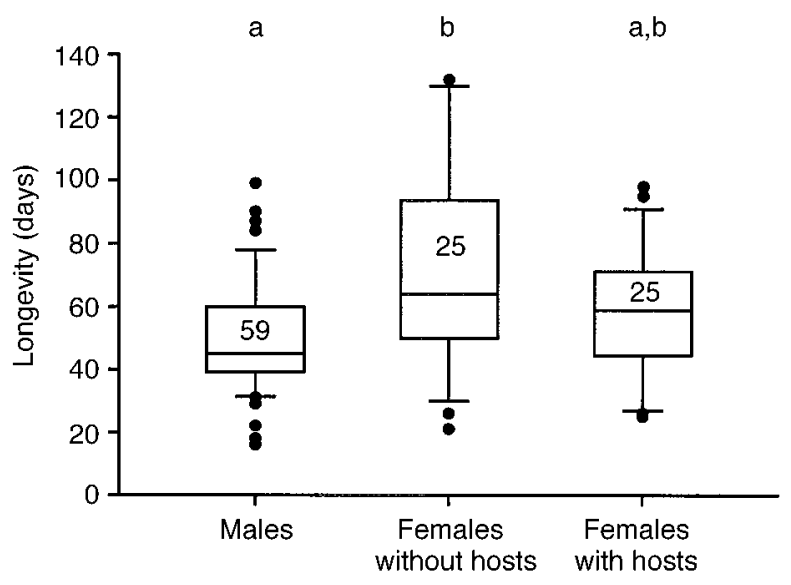

Fig. 1. Longevity of Aptesis nigrocincta males and females at $20^{\circ} \mathrm{C}$. Females were either deprived of hosts but provided with food and water, or used in the lifetime-fecundity test and thus had ad libitum access to food, water and hosts. Different letters above the columns indicate significant differences in longevity, the number within the columns indicates the number of replicates. 


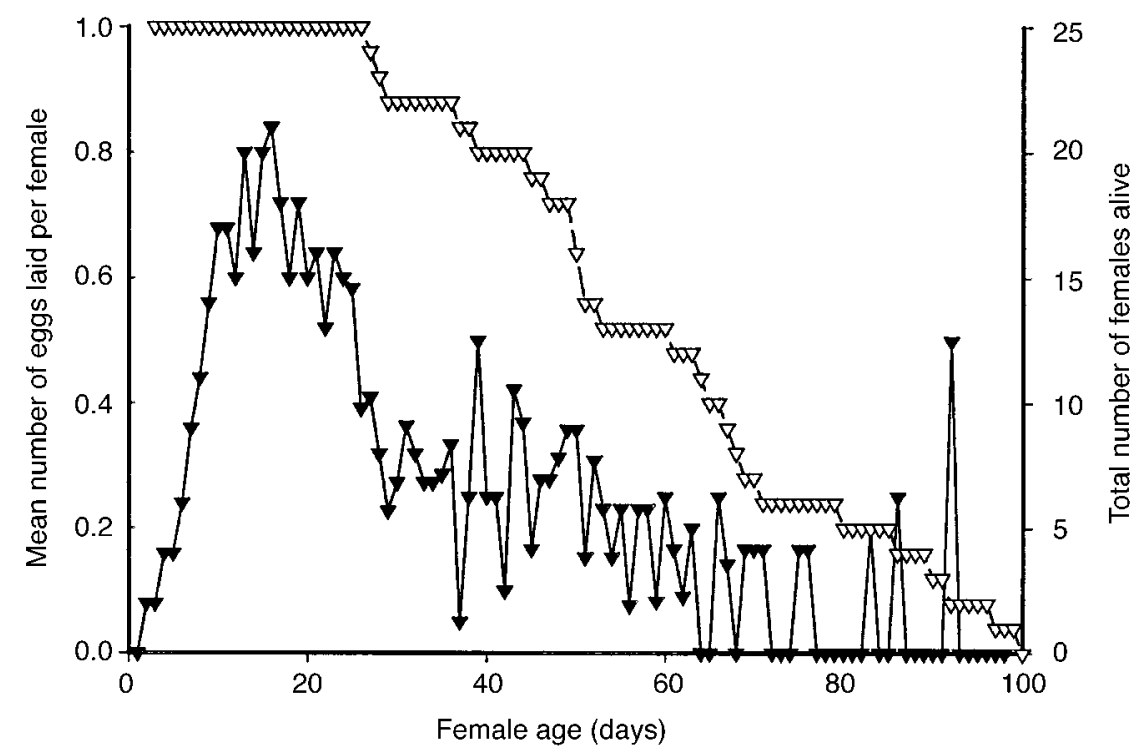

Fig. 2. Life-time fecundity of Aptesis nigrocincta females. Mean number of eggs per female $(\boldsymbol{\nabla})$ that were laid on consecutive days during their lifetime and female survivorship $(\nabla)$. One cocoon was provided to each female every day.

length $\left(Z_{1414}=-3.16, P<0.01\right)$ and $0.246 \pm 0.031 \mathrm{~mm}$ in width $\left(Z_{14,14}^{14,14}=-2.94, P<0.01\right.$, Wilcoxon matched pairs signed rank test). No relationship existed between adult size and either length $\left(\mathrm{F}_{122}=1.74, \mathrm{r}^{2}=0.073, P>0.05\right)$ or width $\left(F_{1,22}=3.08, r^{2}=0.123, P>0.05\right)$ of eggs laid early in the life of $A$. nigrocincta females.

A significant difference in body size, measured as dry weight, between the sexes was obtained if newly emerged males and females are compared $\left(\mathrm{t}_{114}=2.69, P<0.01\right)$ with males being about $15 \%$ heavier than females (see fig. 3 ). The same test for old individuals revealed an even larger bodysize difference of about $25 \%\left(t_{122}=4.20, P<0.001\right.$, see fig. 3$)$.

\section{Field parasitism}

The impact of $A$. nigrocincta on apple sawfly populations was estimated in a field experiment. Rates of parasitism were variable, ranging from 12.1 to $39.7 \%$ in the years of investigation (table 1). Although not negligible, the mortality caused by (unknown) predators or fungi was always less than that of A. nigrocincta, except in the second generation of 1997, where unknown predators accounted for $16.1 \%$ of the mortality (table 1 ). The sex ratio of $A$. nigrocincta appeared slightly male biased in the first generation (significant departure from unity observed only for $1996, \chi^{2}=6.76, P<$ $0.01, n=33$ ), while no departure from the expected $1: 1$ ratio was found in the second generation in the years of investigation.

\section{Discussion}

Several features of the biology of $A$. nigrocincta are typical for an ichneumonid parasitoid of concealed host cocoons (Clausen, 1940) and correspond well with the life history of idiobiont parasitoids (Quicke, 1997): A. nigrocincta is a longlived ectoparasitic species and females lay a small number of

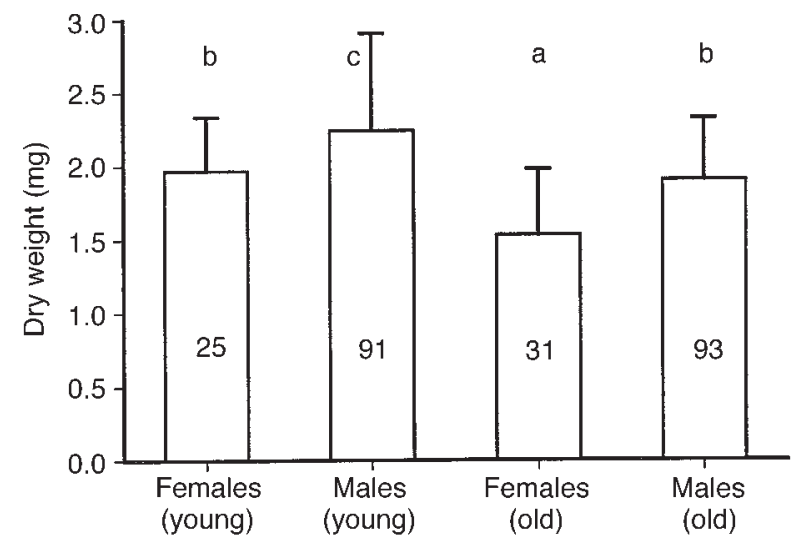

Fig. 3. Dry weight (+ SD) of Aptesis nigrocincta females and males directly after emergence (young) and at death (old). Different letters above the columns indicate significant differences in dry weight, the number within the columns indicate the number of replicates. 
eggs of considerable size. In addition, this species displays a strong sexual dimorphism as is often the case in ichneumonid parasitoids of prepupae or pupae.

The reproductive period of $A$. nigrocincta can be divided into three phases. After a preoviposition period lasting roughly five days, the reproductive rate rapidly increases and remains high for nearly three weeks. Though most females in the laboratory live much longer than four weeks, the number of eggs laid remains low later in the female's life. Similar reproduction curves were obtained by other authors working on parasitoids (e.g. Smith et al., 1990; see also Jervis \& Copland, 1996 for a review).

Smith et al. (1990) investigated the biology of the ichneumonid Mallochia pyralidis Wharton (which also belongs to the subfamily Cryptinae) parasitizing pupae of Eoreuma loftini Dyar (Lepidoptera: Pyralidae). Their findings indicated that females of $M$. pyralidis laid a larger number of eggs per day, and during their entire life, than the A. nigrocincta examined here, even though $M$. pyralidis apparently has a shorter life-span. Investigations of Heterospilus megalopus Marsh (Hymenoptera: Braconidae) (Morales-Ramos \& Cate, 1993) have shown that this is one of the very few known parasitoid species that produce fewer progeny per day than A. nigrocincta. Although $H$. megalopus has a longer pre-oviposition period than $A$. nigrocincta, and the longevity of both species is similar, the braconid lays more eggs in its life than A. nigrocincta, due to a longer phase of high reproduction. Two Ichneumon spp. attacking pupae of Lepidoptera (Hinz, 1991), and Pimpla nipponica Uchida (Hymenoptera: Ichneumonidae) (Ueno, 1999a), have been shown to have maximum egg maturation rates of one egg per day, much like $A$. nigrocincta. As for the abovementioned species, this low rate of daily egg-maturation appeared to be an adaptation to a low encounter rate of hosts by $A$. nigrocincta in the field.

If $A$. nigrocincta females are really limited by their chances of finding hosts, selection tends towards larger eggs because of the associated advantages that Quicke (1997) outlined for parasitoids (see also Rosenheim, 1996). Aptesis nigrocincta in fact produce voluminous eggs that are even larger than those produced by females of the congeneric A. abdominator Gravenhorst (Hymenoptera: Ichneumonidae) (Sechser, 1970). The decrease in egg-size at the end of the oviposition period observed for $A$. nigrocincta is most likely due to resource depletion. If the observed decrease is the genetically fixed result of selection pressure pointing to smaller eggs later in life, a linear rather than a discontinuous pattern would have been expected as has been shown in butterflies (Karlsson \& Wiklund, 1984).

Female fitness, measured most often as eggload or lifetime fecundity in the laboratory, is often found to increase with adult size (e.g. Visser, 1994; West et al., 1996). This has been shown explicitly in synovigenic species (Rosenheim \& Rosen, 1991), such as Aphytis lignanensis Compère (Hymenoptera: Aphelinidae), where maximum eggload was correlated with adult size (see also Ueno, $1999 b)$. The present study is one of the few examples where adult size of females was not correlated with either lifetime fecundity or longevity. However, only small size differences were found in apple sawfly cocoons in the present study, and consequently the variation in body size of females reared on these hosts was minor compared with parasitoids used in other studies (such as Aphytis in Rosenheim \& Rosen 1991; see also Leather, 1988). Visser (1994) points out that female fitness might depend on factors other than fecundity and longevity, but suggested the best parameter for female fitness will be lifetime fecundity in the field. Usually, under field conditions, a smaller increase in female fitness with female size is obtained compared with results from the laboratory (Visser, 1994; West et al., 1996). As the present study did not show such an effect even in the laboratory, it seems unlikely that such a correlation exists in the field. Additionally, the fact that males are heavier than females suggests there may be greater selection pressure on male than on female size.

Aptesis nigrocincta was the most important mortality factor of apple sawfly cocoons in the field exposure experiment. Assuming that females of the second generation could potentially attack only those cocoons that remained healthy after the first exposure period (i.e. 82.7\% in 1996 and $65.3 \%$ in 1997) the mortality on the univoltine host caused by two cumulative generations of $A$. nigrocincta might have been about $45 \%$ in 1996 and $26 \%$ in 1997. However, the number of cocoons exposed in the field experiment represents a high host density, and without any knowledge of the response of $A$. nigrocincta to host density, it could not be ruled out that the parasitism rate under natural conditions might differ. Furthermore, females might have had a differential chance of finding hosts exposed within the wooden frames compared with hosts naturally present in the orchard. On the one hand, the soil within the wooden frames lacked the trails of the host larvae that entered the soil, which may be important for host location. On the other hand, the soil was less compressed in the frames than in the field, making access to host cocoons easier.

To summarize, $A$. nigrocincta is a long-lived parasitoid of apple sawfly cocoons that, in spite of a rather low fecundity, caused significant mortality of its host. While this appeared promising in terms of using this natural enemy as a biological control agent against apple sawfly in Canada, other critical traits require further research. For instance, dispersal capacity is considered to be an important trait in biological control programmes but may be quite low in this parasitoid species with its wingless females. Furthermore, the host specificity of A. nigrocincta cannot conclusively be determined from the literature, and should be evaluated further. Finally, possible detrimental effects to the koinobiont larval parasitoid L. ensator via interspecific competition have to be investigated before introducing this parasitoid into a new geographic location.

\section{Acknowledgements}

I would like to thank Mr Kurt Schnider who generously allowed the exposure of cocoons and the collections of infested apples in his orchard near Zuckenriet. The help of Stephanie Erb, Nancy Otten, Katja Rietdorf and Shawna Paddle with the field work was greatly appreciated. Many thanks to Ulrich Kuhlmann, Liam Lynch, Klaus Carl, Jean-Luc Boevé and two anonymous reviewers for their suggestions on earlier drafts of this manuscript. I would like to thank Charles Vincent, the project counterpart in Canada for his collaboration and Agriculture Agri-Food Canada for funding.

\section{References}

Babendreier, D. (1999) Observations on the biology and phenology of Aptesis nigrocincta (Hymenoptera: 
Ichneumonidae) parasitizing cocoons of the apple sawfly, Hoplocampa testudinea (Hymenoptera: Tenthredinidae). Bulletin IOBC/ WPRS 22, 57-61.

Carl, K.P. (1976) The natural enemies of the pear slug, Caliroa cerasi (L.) (Hymenoptera: Tenthredinidae) Zeitschrift für Angewandte Entomologie 80, 138-161.

Clausen, C.P. (1940) Entomophagous insects. 688 pp. New York, McGraw-Hill Book Co.

Hinz, R. (1991) Untersuchungen zur Lebensweise von Arten der Ichneumonini (Hymenoptera: Ichneumonidae) Mitteilungen der Schweizerischen Entomologischen Gesellschaft 64, 109-114.

Horstmann, K. (1993) Revision der brachypteren Weibchen der westpaläarktischen Cryptinae. Entomofauna 14, 85-148.

Jaworska, M. (1987) Observations on Lathrolestes marginatus (Thompson), a parasitoid of the apple sawfly - Hoplocampa testudinea (Klug) (Hymenoptera: Tenthredinidae). Polskie Pismo Entomologiczne 57, 553-567.

Jervis, M.A. \& Copland, M.J.W. (1996) The life cycle. pp. 63-162 in Jervis, M.A. \& Kidd, N.A.C. (Eds) Insect natural enemies. London, Chapman and Hall.

Karlsson, B. \& Wiklund, C. (1984) Egg weight variation and lack of correlation between egg weight and offspring fitness in the wall brown butterfly, Lasiommata megera. Oikos 43, 367-385.

Kopelke, J.P. (1986) Zur Taxonomie und Biologie neuer Pontania-Arten der Dolichura-Gruppe. Senckenbergiana Biologia 67, 51-71.

Leather, S.R. (1988) Size, reproductive potential and fecundity in insects: things aren't as simple as they seem. Oikos 51, 386-389.

Morales-Ramos, J.A. \& Cate J.R. (1993) Reproductive biology of Heterospilus megalopus (Hymenoptera: Braconidae), a parasitoid of Anthonomus grandis. Annals of the Entomological Society of America 86, 734-739.

Ohnesorge, B. (1957) Untersuchungen über die Populationsdynamik der kleinen Fichtenblattwespe, Pristiphora abietina (Christ.) (Hymenoptera: Tenthredinidae) 1. Teil, Fertilität und Mortalität. Zeitschrift für Angewandte Entomologie 40, 443-493.

Quicke, R.D.L.J. (1997) Parasitic wasps. London, Chapman and Hall.

Rosenheim, J.A. (1996) An evolutionary argument for egg limitation. Evolution 50, 2089-2094.

Rosenheim, J.A. \& Rosen, D. (1991) Foraging and oviposition decisions in the parasitoid Aphytis lingnanensis: distinguishing the influence of egg load and experience. Journal of Animal Ecology 60, 873-893.

Sechser, B. (1970) Der Parasitenkomplex des kleinen Frostspanners (Operophtera brumata L.) (Lepidoptera: Geometridae) unter besonderer Berücksichtigung der Kokonparasiten, 1. Teil. Zeitschrift für Angewandte Entomologie 66, 144-160.

Smith, J.W. Jr., Rodriguez del Bosque, L.A. \& Agnew, C.W. (1990) Biology of Mallochia pyralidis (Hymenoptera: Ichneumonidae), an ectoparasite of Eoreuma loftini (Lepidoptera: Pyralidae) from Mexico. Annals of the Entomological Society of America 83, 961-966.

Ueno, T. (1999a) Reproduction and host-feeding in the solitary parasitoid wasp Pimpla nipponica (Hymenoptera: Ichneumonidae). Invertebrate Reproduction and Development $35,231-237$.

Ueno, T. (1999b) Adult size and reproduction in the ectoparasitoid Agrothereutes lanceolatus Walker (Hymenoptera: Ichneumonidae). Journal of Applied Entomology 123, 357-361.

Vincent, C. \& Mailoux, M. (1988) Abondance, importance des dommages et distribution de 1'hoplocampe des pommes au Quebec de 1979 a'1986. Annales de la Société Entomologie de France 24, 39-46.

Visser, M.E. (1994) The importance of being large: the relationship between size and fitness in females of the parasitoid Aphaereta minuta (Hymenoptera: Braconidae). Journal of Animal Ecology 63, 963-978.

Waage, J.K. (1990) Ecological theory and the selection of biological control agents. pp. 135-157 in Mackauer, M., Ehler, L.E. \& Roland, J. (Eds) Critical issues in biological control. Andover, UK, Intercept.

West, S.A., Flanagan, K.E. \& Godfray, H.C.J. (1996) The relationship between parasitoid size and fitness in the field, a study of Achrysocharoides zwoelferi (Hymenoptera: Eulophidae). Journal of Animal Ecology 65, 631-639.

Zajanckauskas, P. (1963) Obuolinio piuklelio (Hoplocampa testudinea Klug) vystymosi stebejimai Lietuvoje. Lietuvos TSR Aukstuju Mokyklu Mosko Darbai 1, 39-42.

(Accepted 9 June 2000)

(C) CAB International, 2000 


\section{Sampling and Monitoring in Crop Protection: The Theoretical Basis for Designing Practical Decision Guides}

M R Binns, Agriculture and Agri-Food Canada, Ottawa, Canada, I P Nyrop, Department of Entomology, Cornell University, USA, and $W$ van der Werf, Subdepartment of Theoretical Production Ecology, Wageningen Agricultural University, Netherlands

March $2000 \quad 304$ pages HB

ISBN 0851993478

$£ 49.95$ (US\$90.00)

Readership: Graduate or final year undergraduate students and professionals in pest management/crop protection.

This book covers the statistical concepts of sampling in agricultural pest management. These can be summarised as how to obtain sample data from the field and how to use the data in decision-making. Options may include introducing natural enemies, spraying with pesticide, or adopting a wait-and-see approach. Some prior knowledge of pests and how they interact with crops is required of the reader, but only minimal mathematical background is assumed. Worked examples using the mathematical software program Mathcad are also included.

Contents include:

- Basic concepts of decision-making in pest management

- Basic concepts of sampling for pest management

- Classifying pest density

- Distributions

- Sequential sampling for classification

- Enhancing and evaluating the usefulness of sampling plans

- Binomial counts

- Multiple sources of variation

- Resampling to evaluate the properties of sampling plans

- Sampling over time to classify or estimate a population growth curve

- Monitoring pest populations through time

$$
\begin{aligned}
& \text { For further information or to order please contact CABI Publishing, UK or an exclusive CABI Publishing } \\
& \text { distributor in your area. } \\
& \text { Please add } £ 2.50 \text { per book postage and packing (excluding UK). }
\end{aligned}
$$

\section{CABI Publishing}

CABI Publishing, CAB International, Wallingford, Oxon OX10 8DE, UK

Tel: +44 (0)1491832111 Fax: +44 (0)1491829292 Email: orders@cabi.org

CABI Publishing, CAB International, 10 East 40th Street, Suite 3203, New York, NY 10016, USA

Tel: +1 2124817018 Fax: +1 2126867993 Email:cabi-nao@cabi.org 